IJCCS (Indonesian Journal of Computing and Cybernetics Systems)

Vol.13, No.1, January 2019, pp. 95 104

ISSN (print): 1978-1520, ISSN (online): 2460-7258

DOI: https://doi.org/10.22146/ijccs.43066

\title{
Apps-based Machine Translation on Smart Media Devices - A Review
}

\author{
Hary Gunarto*1 \\ ${ }^{1}$ Ritsumeikan Asia Pacific University, Beppu, Japan

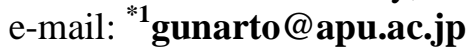

\begin{abstract}
Abstrak
Mesin Penerjemah pada telepon pintar merupakan bagian dari Natural Language Processing (NLP) yang memungkinkan kita dapat berkomunikasi menggunakan bahasa ibu kita masing-masing. Makalah ini membahas tentang perkembangan terbaru dari mesin penerjemah yang banyak digunakan oleh pengguna Internet saat ini. Masalah kualitas dan keakuratan hasil terjemahan dari penerjemah berbasis web \& Aplikasi ini akan dipresentasikan dan didiskusikan. Pembahasan mengenai beberapa alat dan teknologi pemrograman juga dilakukan agar supaya peangkat lunak tersebut mampu menganalisis dan menghasilkan terjemahan yang baik dan sempurna. Tantangan di masa depan untuk membuat aplikasi perangkat lunak yang pintar ke arah AI dan NLP masih perlu dikembangkan dan diusahakan terus lewat kolaborasi antara para ilmuwan komputer dan ahli bahasa.
\end{abstract}

Kata kunci-Machine Translation, Natural Language Processing, Apps-based MT, Smart Media Device

\begin{abstract}
Machine Translation Systems are part of Natural Language Processing (NLP) that makes communication possible among people using their own native language through computer and smart media devices. This paper describes recent progress in language dictionaries and machine translation commonly used for communications and social interaction among people or Internet users worldwide who speak different languages. Problems of accuracy and quality related to computer translation systems encountered in web \& Apps-based translation are described and discussed. Possible programming solutions to the problems are also put forward to create software tools that are able to analyze and synthesize language intelligently based on semantic representation of sentences and phrases. Challenges and problems on Apps-based machine translation on smart devices towards AI, NLP, smart learning and understanding still remain until now, and need to be addressed and solved through collaboration between computational linguists and computer scientists.
\end{abstract}

Keywords-Machine Translation, Natural Language Processing, Apps-based MT, Smart Media Device

Received January $28^{\text {th }}, 2019 ;$ Revised January $30^{\text {th }}$, 2019; Accepted January $31^{\text {th }}$, 2019 


\section{INTRODUCTION}

Global communications among people with different languages is growing in recent times in our communities and in social media and networks. Communication and sharing of information with people in different countries is vital to many international organizations such as United Nations, European Union and other institutions in order to support their work and activities. Staff and personnel working in these organizations are quite often involves with different peoples in certain regions and around the world in general. But, they frequently face some difficulties when interacting and exchanging ideas with them due to language problems, especially in English as one of our major worldwide languages.

Moreover, social and economic interaction among people from different countries has also become popular in our day to day activities, which grow with recent social and economic globalization. Economic crisis in the US and some countries in European Union shook many economies all over the world. In such situations, it is important to immediately know and respond to what is happening worldwide. Another example in business and commercial world, many people lately buy products from online-shopping websites such as ebay.com, alibaba.com, rakuten.co.jp, gmarket.co.kr, etc. Internet shoppers and customers who searched and accessed such webservers may come from different regions with different spoken languages. Since most information and on-line content on the servers is presented in English or other local language on which they don't quite understand, they prefer and expect obviously to get the information in their own language. In such conditions, they often use computers to get help for translation, and rely on human-computer interactions [1].

Human-computer interaction as a branch of machine translation systems can be specifically developed for such purposes. Also known as man-machine interface, human computer interaction is commonly implemented in interactive software such as in web-browsers (Google Chrome) and other software tools linked to social networking systems (SNS) i.e. Twitter, Facebook, LinkedIn, Tumblr, Instagram, Pinterest, etc. Although translation software still has a few problems with many unclear translation outcomes, Internet users are forced to accept the existing translation result. In efforts to make the translation better and reliable, linguist and computer scientists should joint hands and work together to address the difficulties and challenge of improving machine translation systems to express correct and precise information [2].

Although research on Natural Language Processing began in the early 1950s, serious research activities on this subject are still being pursued in many countries to address the translation process into their own language. In the1980s, The Center of International Cooperation for Computerization (CICC) in Japan developed a translation machine with the interlingua (lingua franca) approach, as described in [3]. This translation system has one-to-one translation, and it is also capable of doing multilingual translation. The CCIC system developed in an interlingua model which covered five languages: Indonesian/Malay, Thai, Chinese, Japanese and also English. These original five languages can be set as either source or target language, and be connected one to another language using English as the interlingua base. Later on, CICC considered adding German, French and other European languages to enable and develop CICC interlingua to not only be Asiaversal.

Besides CCIC system, several research efforts to develop man-machine interfaces for certain applications have been made for Indonesian language and its local dialects, for example, by Indonesian Telecommunication Company (P.T. Telkom) which tried to build text-to-speech for its services in the Indonesian language. This research work translated all computer terminology into Indonesian terms, and then, all these terms had to be synthesized in order to give the correct pronunciation. Other work in language translation between Indonesian and the local Javanese language with four speech levels of politeness was also reported. In 2013, [4] described that the preliminary outcome of their research on translation from Javanese to Bahasa Indonesia gave more accurate results than translating in the opposite direction with an accuracy

IJCCS Vol. 13, No. 1, January 2019: $95-104$ 
of $63 \%$ to $83 \%$. Other efforts for languages in Indonesia are still undertaken recently to make the translation process better, more accurate and efficient [5] and [6].

In recent times, information, knowledge and educational texts are mostly written in English and other European languages. Since English is spoken and used worldwide, this benefits millions of people. But, non-English speakers have some difficulties to understand those texts and materials. For them, it would be better to get the information in their own native language. To achieve that goal, they commonly use computer or machine translation systems. Different kinds of computer programs linked to the Internet browsers, social media servers and other language toolkits are utilized to assist their translation. Due to demands for such services, the use of this machine translation will help to solve their language problem when they access the information on Internet.

At present, machine translation systems are useful under limited situation and conditions. Very often, the translation result of most Internet documents has to be edited, and requires further corrections on the output files to give perfect outcomes. In transmitting information to global users, the sender (website) often does not know the language of the clients/recipients. On the servers, the websites try to use machine translation systems (www.amazon.com and www.rakuten.co.jp offer English, Chinese and other translations), and frequently these websites cannot check whether the translated results are correct or not.

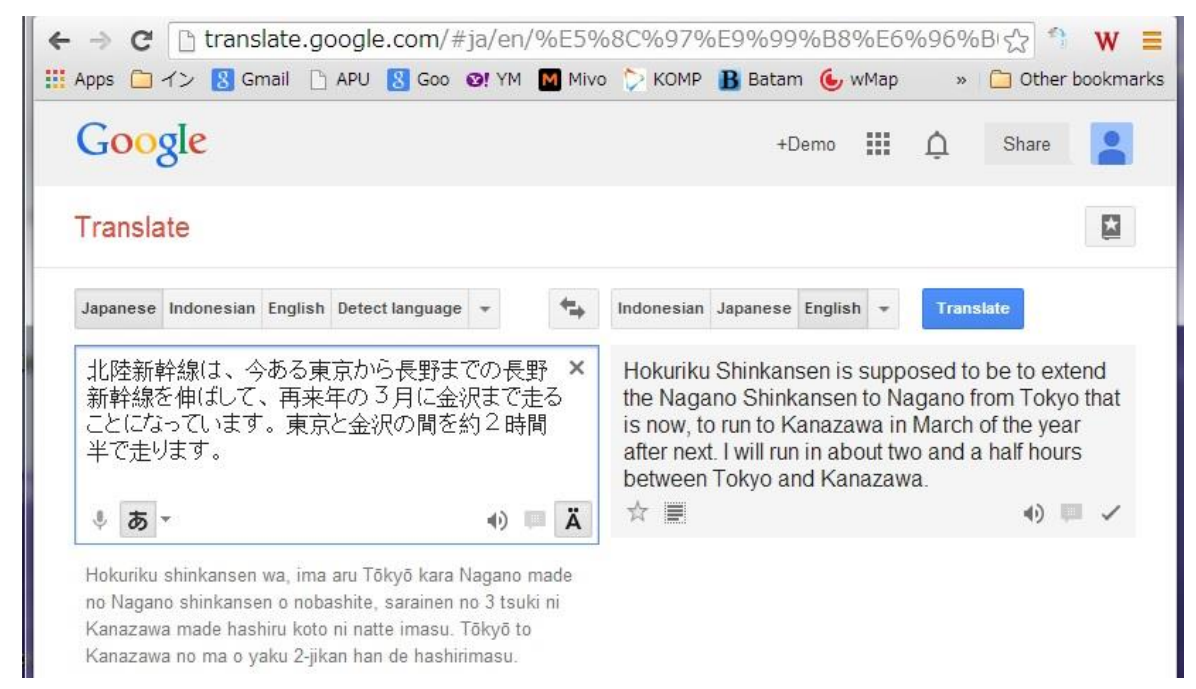

Figure 1. Unassisted MT Translation from Japanese to English by Google.com

In general, Machine Translation (MT) can be divided into two types: unassisted MT and assisted MT. Unassisted MT takes pieces of document and translates them into final output for direct use without human intervention. The result is often imperfect text and gives only a general idea of the document as direct translation of source language, word by word, as shown in Figure 1 and 2. Furthermore, unassisted MT systems can be represented as corpus-based machine translation (CBMT) and as rule-based machine translation (RBMT). RBMT in general is based on linguistic, semantic, morphological, and syntactic information, and on the other hand, CBMT can be derived from large bilingual texts of examples. Moreover, CBMT is split into statistical machine translation (SMT) and example-based machine translation (EBMT). Below, several popular unassisted MT systems can be found, for example in: Google Translate (based on SMT) https://translate.google.com; Bing Microsoft Translator (based on SMT) https://www.bing.com/translator; Watson Language Translator (SMT \& RBMT) https://www.ibm.com/watson/services/language-translator/

IdiomaX (RBMT), Asia Online (SMT), PROMT Translation Systems (RBMT), etc. Between these systems, the quality of its translations can be compared and predicted using some models such as QuesT framework, as reported in [7]. 


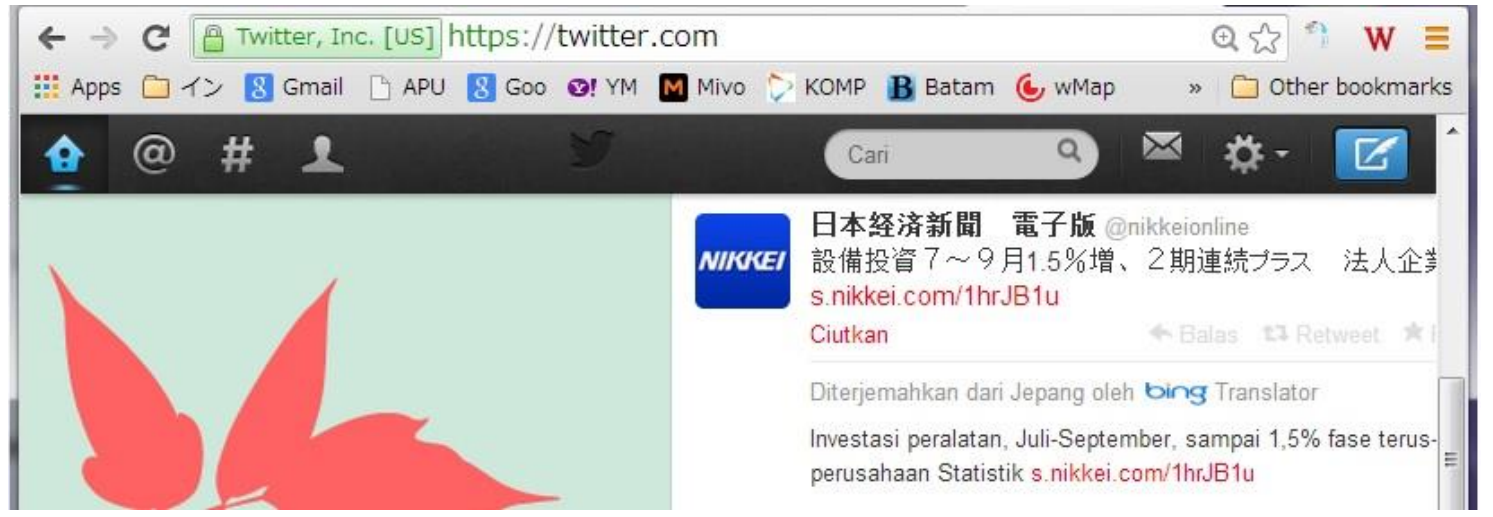

Figure 2. Unassisted MT from Japanese to Indonesian on Twitter by Bing Translator

The second type of Machine Translation is assisted MT that uses human translators to clean up before, and also after the translation process in order to get better results. Generally, the translation process is improved by limiting the vocabulary through use of a selected dictionary/words and types of grammar or sentences allowed. So far, this system has been fairly successful and some systems have also been installed and used in the educational institutions for language learning and training. The assisted MT can be Machine Aided Human Translation (MAHT), human that use computer help; or it can be Human Aided Machine Translation, a computer that requires human help. Sometimes, MAHT is also known as Computer Aided Translation (CAT). Nevertheless, assisted MT is also still challenging in current computer technology that demonstrates their limited acceptance [8].

The difficulty in assisted translation systems lies in the language analysis process to be performed by the machine and computer software. In analyzing a sentence to its semantic expression, the computer has to discriminate the lexical and syntactic ambiguities, and afterward, derive the correct semantic/meaning representation. There are some problems to be solved in these processes and some of the most difficult ones are related to the translation of sophisticated sentences [9]. Only with correct choice of MT engine and Translation Memory used such as in Bing, Google, Apertium, Lucy, Moses, Systran, Babylon, Asia Online, IBM, PROMT, Reverso System, and so on, can translation quality be accurate enough and give good results [10].

The construction of assisted MT systems varies but all use some kind of transfer or intermediate component. This component is designed so that a pair of languages can produce a perfect target sentence. The transfer component has a correspondence of lexicon, and consists of a complete list of source-language phrases mapped to a target/ intended language. Some of the MT systems use transfer methods, which allow software parsers to analyze and evaluate the source language phrases/expressions. Using this sort of transfer system, a new corresponding lexicon can be created for every two languages to be translated. A translation is then made from the source language into transfer component or interlingua and then into the target language. An advantage of using such interlingua /lingua franca is that only one segment is required for each language translation and therefore new languages can be easily added. Several research organizations have implemented this transfer scheme in building their translation systems, including the early version of Fujitsu ATLAS Translation v.14, and the Language Translation System created by Distributed Language Group (DLG) [11].

The most cited transfer (lingua franca) system is called Universal Networking Language (UNL) developed under the support of United Nations and United Nations University (UNU) in Tokyo in the early of 2000s. UNL is designed as an artificial language in the form of a semantic network to express and exchange every kind of information. Many translation systems have been developed by various research organizations based on UNL expressions as its common transfer language for their computer systems. With the increasing development efforts on UNL,

IJCCS Vol. 13, No. 1, January 2019: $95-104$ 
any past research endeavors and achievement can be used to enhance future development for more comprehensive language translation systems that cover all our languages worldwide.

Technically, UNL expresses information into meaning, sentence by sentence. Each sentence of text is represented as a hyper-graph having concepts as nodes and relations as arcs. This hyper-graph is then expressed as a set of directed binary relations, each between two concepts contained in the sentence. Concepts are denoted as character-strings called "Universal Words", and Universal Words can be annotated with attributes, which give further information on how the concept is being used in this specific sentence. As results, UNL documents will consist of an extensive list of relations between idea/concepts on that language pair, e.g. as presented in [12], from Standard Moroccan Amazigh language to UNL and vice versa.

\section{METHODS}

Programming languages such as Visual Basic, php, webRTC, JavaScript, HTML5, etc. are commonly used as basic tools to create natural language processing and translation programs that fit user needs. These programming languages allow programmers to write and develop translation software applications, which are not commonly available and automatically included in any standard software package (such as word-processing, spreadsheet, presentation systems, and web publishing). This research work presents several translation systems such as, Multiple Languages and Kanji Dictionary used for language training which were created using Visual Basic (on stand-alone desktop) and web-based php-MySQL programs as shown in Figures 3, 4 and 5 reported in [3] \& [13].
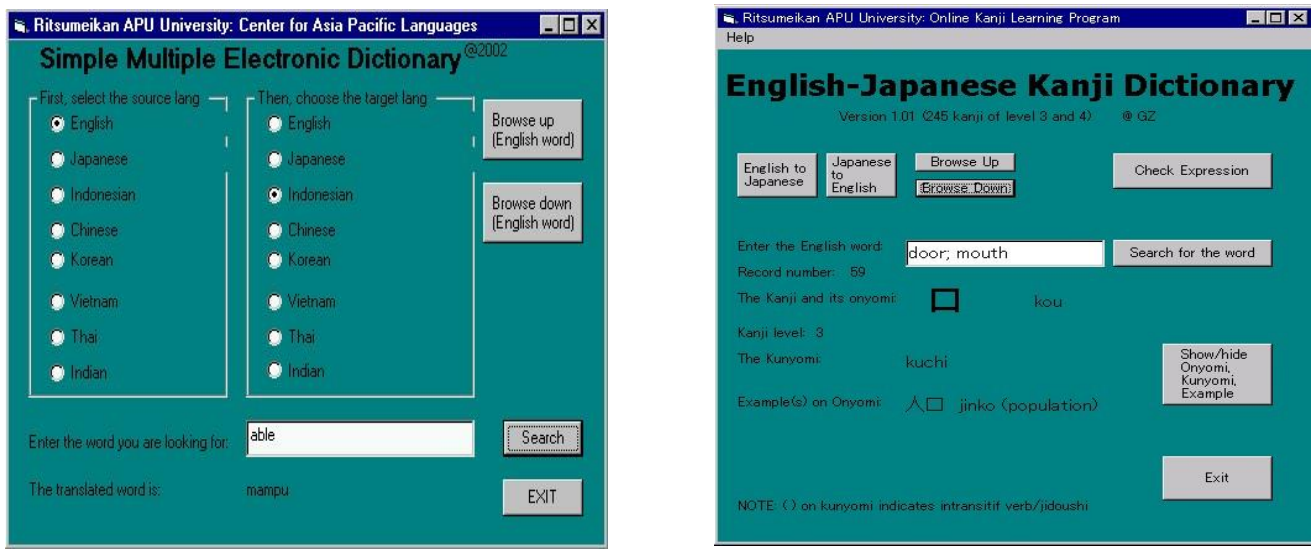

Figure 3. Desk-top Multiple Languages and Kanji Dictionary

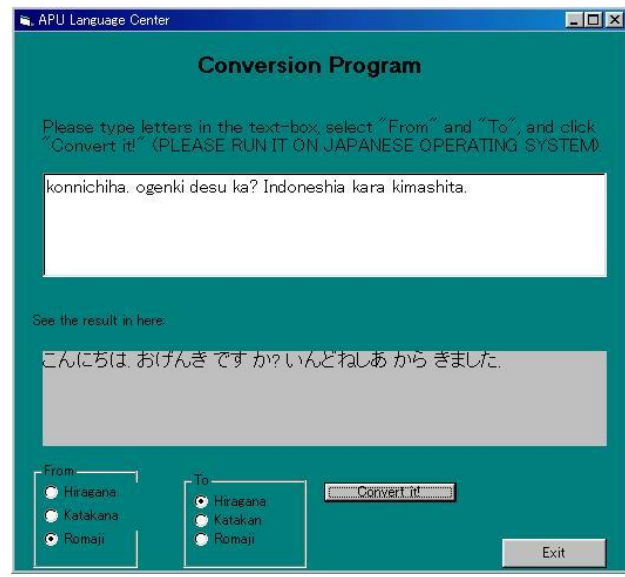

Figure 4. Hiragana and Roman Characters Conversion Program 
Another programming tool called WebRTC (Web Real-Time Communication) was proposed by the World Wide Web Consortium (W3C) and used by Google Technical Groups to realize Internet-based browser-to-browser applications for real time voice communications, video chat, and P2P (peer to peer) file sharing. The WebRTC is an API (Application Programming Interface) definition currently designed to run on Google Chrome, Mozilla Firefox, and Opera web browsers to enable access to data from camera and microphone for audio/video calls. With such W3C definitions, voice/video frames are streamed directly between peers, without any server in between as opposed to traditional communication with a shared relay server in the network. The effect of webRTC's usage together with Distributed Hash Table (DHT)-based translation in Google-translate services is a lower latency time in the translation process and more efficient network utilization which outperforms HTML5 capabilities [14].

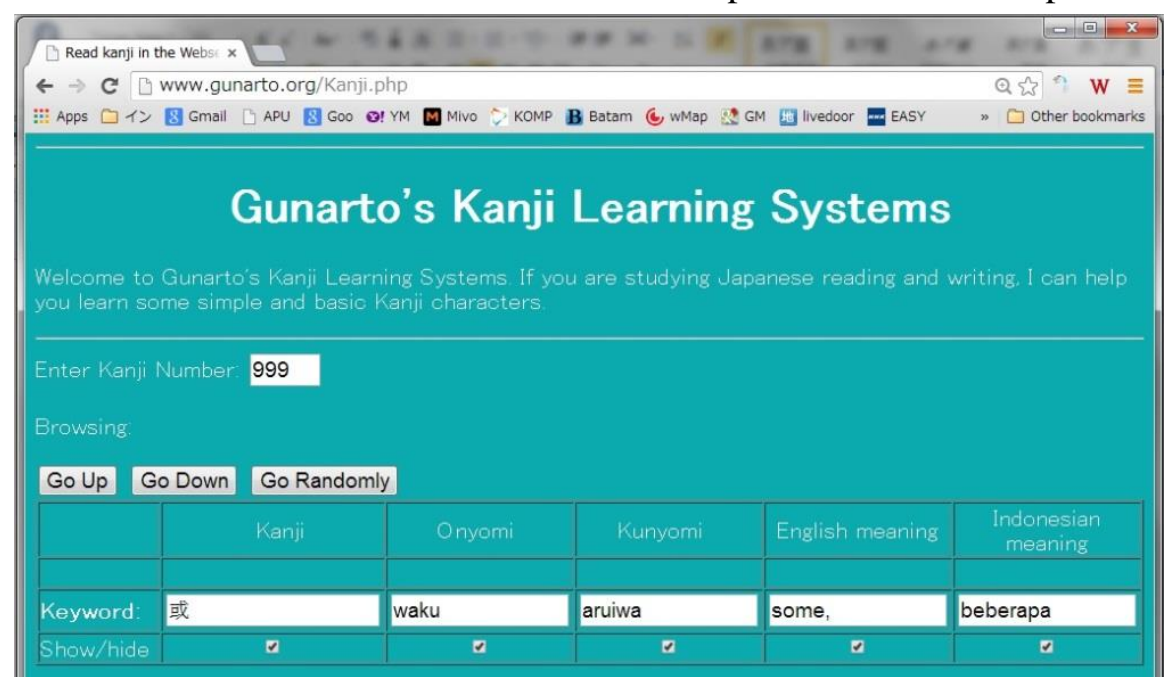

Figure 5. Internet-based Kanji Learning Program created with php-MySQL

Other tool, JavaScript API, is used by Microsoft Research Team to demonstrate machine translation and natural language processing called Bing Translator that achieves improving quality on their machine translations. With a wide range of potential translation applications, the JavaScript API (designed for MS-Windows and Microsoft Office) allows software developers to use and to provide methods for signing users in and out, getting user status, subscribing to events, creating User Interface controls, etc. The Bing translator API provides automated translation of web pages into 65 different languages including Arabic, African, English, French, German, Polish, Russian, Japanese, Chinese and Korean. The Microsoft team plans to add more languages over time. This JavaScript API can also provide several basic ways for accessing data in a client-side MS-Office file to get and set the selected data, or to get access to the entire range of documents [15].

With the advance of smart devices, many new services offer translation for small and portable gadgets and equipment. Recently, demand for sharing of web contents via all different types of smart machines (smartphone and tablets) is increasing. However, the compatibility between these smart phones, phablet and tablet devices still has technical problems. The possible solutions are using HTML5 and binary translation. Use of HTML5 is a common technique for realizing translation on an independent platform of smartphone applications. Moreover, binary translation is often implemented to translate the binary data from a specific platform to another target hardware machine. Another type of programming tool called Smart TV application can also be adapted to run smart translation applications on web-enabled TV through Internet networks [16]-[17].

The quality and accuracy of information obtained from any Internet or web-based translation, in general depends not only on the features of the programming/software tool itself, but also on the data entered in the database associated to linguistic problems to be solved. Even

IJCCS Vol. 13, No. 1, January 2019: $95-104$ 
until now, some minor problems still exist from the language perspective, on which there are words with ambiguous and competing meanings (e.g. light which can mean either bright or weightless); problems of sentences with complex grammatical structures; and other problems coming from idioms. All these factors contribute to mistranslation so that we often end up with very odd results that require further efforts to make them into better, more intelligent and smarter translation outcome.

\section{RESULTS AND DISCUSSION}

As result of this research and based on translation systems presented in previous section, we will review and discuss on machine translation systems needed for various services in current digital world and in many aspects of our life. With the spreading use of smart media devices such as smart phones, tablets, phablets, smart watches, and smart clothing, machine translation systems have importance for those small gadgets that often come with voice recognition, voice understanding and voice synthesis technology. Furthermore, these smartphones and wireless networks accelerate the use of hand writing \& image recognition, location-based (L-based) service and mobile-cloud computing [18].

Using wireless networks serving as recent global information infrastructure, NLP on smart devices becomes feasible and grows into an essential medium to facilitate comfortable and convenient communication. Such smart media NLP services allow translation from any user locations and provide easy communication among people for all kinds of activities. Hence several NLP systems have been developed recently running on smart mobile platforms with mobile-phone Operating Systems (O/S) such as iOS (iPhone), Android, Windows 10 Mobile, BlackBerry Secure, Chrome OS, Ubuntu Touch, etc. With OS similarly installed in desktop computers, smart media devices become more intelligent and reliable and run faster than earlier generations. Nowadays, they can be used to support many applications and services, namely:

- Multilingual Information Service

- GPS, Maps and Geographical Information System

- Information Search and Retrieval System

- Knowledge based Search Engine, and Intelligent \& Expert Systems [19].

These smart devices and Apps-based mobile computing generally are becoming the flourishing technology and growing into the latest trend and new lifestyle among people, especially among younger generations for their everyday activities so that they can communicate and access information faster and more reliably than before. Mobile computing devices are usually connected to a secure mobile phone network and public Internet which constantly increase in speed and coverage. Mobile computing is developed on the convergence of wireless technologies, advanced 4G (LTE) cellular phone network technology and the Internet technology. Consequently, wherever the place and location of mobile users is, the data will be immediately available at any time from their locations. Even some new features that mobile users have never imagined before related to voice and video calls and communication are now being easily realized through mobile computing.

Our smart media devices are currently able to translate not only from text messages, but also from voice/spoken language (using its microphone), and even from an image/picture taken through its camera along with OCR (Optical Character Recognition) technology. Smart and intelligent mobile App (application) software such as Google Voice Search, Google Mobile Translator, Bing Translator, etc. give us near true NLP with almost accurate translation and allow faster information access without complicated data typing on its small onscreen keyboard. In Figure 6(a), smartphone translation from English to Japanese activated from spoken language on its microphone is shown using "Voice Translator" App software, and it showed that the translation is often still imperfect. In Figure 6(b), Google search is presented as voice-based search running on the same smartphone. Many language translation Apps are easily available now and are being offered to all smart mobile phone users as shown in Table 1 through Google Play, App Store, Windows Store, etc. 

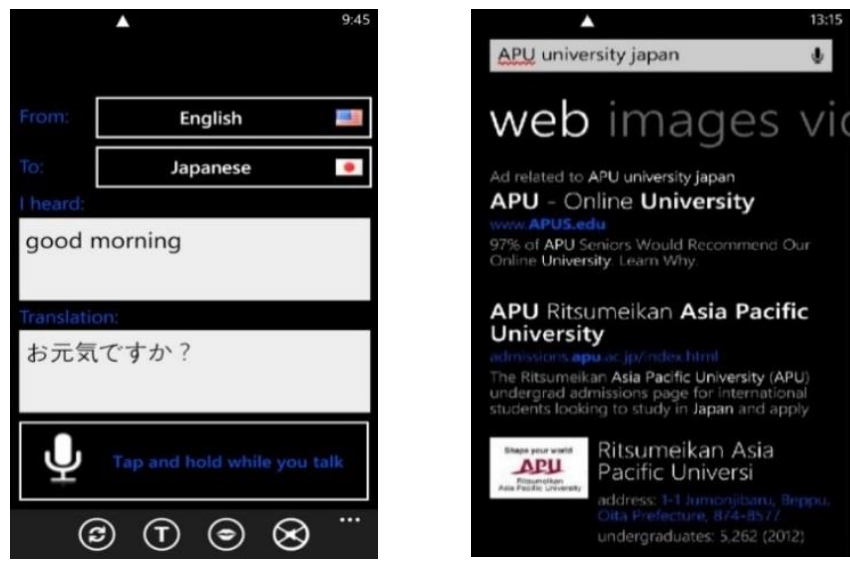

Figure 6. (a) Voice-activated Translation from English to Japanese (b) Google Voice-based Search

Table 1. Popular Translation Apps for Smartphones

\begin{tabular}{|l|c|l|}
\hline \multicolumn{1}{|c|}{ App's Name (Operating System) } & \# of supported Lang & \multicolumn{1}{c|}{ Input Types $*$ ) } \\
\hline Google Translate (for Android, iOS) & 103 (32 instant) & T; I; V; H; O \\
\hline Bing Translator (iOS, Android, Watch OS, Wear OS) & 65 & T; I; V; O \\
\hline Navita Translator (BlackBerry) & 52 & T; V \\
\hline iTranslate (Android, iOS, Watch OS) & $90+$ & T; I; V; O \\
\hline Universal Translator (Android) & 40 & T; V \\
\hline SayHi Translate (Android, iOS) & 90 & T; V \\
\hline Jibbigo Translator (Android, iOS) & $20+$ & T; V; O \\
\hline VerbalizeIt (Android, iOS) & 150 & T; V \\
\hline MyLanguage Translator Pro (iOS) & 59 & T; V \\
\hline IdiomaX (Android, iOS, Windows Mobile) & 5 & T; I; O \\
\hline PROMT (Android, iOS) & 15 & T; I; V; O \\
\hline $\begin{array}{l}\text { *) T: translate from text (keyboard); I:from image/OCR (camera); V:from voice; H:from } \\
\text { handwriting; O: Off-line }\end{array}$ & \multicolumn{2}{|l}{} \\
\hline
\end{tabular}

Moreover, cloud computing for mobile devices becomes a new paradigm in the field of mobile computing. With technological shift from traditional cellular applications to new mobile cloud computing, this technology improves software application performance, accuracy and efficiency by transferring complicated data and tasks onto powerful computing platform machines. By running and executing only simple tasks on smart mobile devices, we can achieve a faster access and get a greater processing efficiency. This cloud parallel processing approach provide not only quick solutions, but it can also be used to solve problems on large datasets. Within a group of computers on a connected network, there are collections of webservers, and we have the ability to access files of information on wide varieties of cloud systems. Nowadays mobile and IoT (Internet of Things) users need not know how their jobs are actually executed in distributed environments and they need not take into account their cloud hardware platforms [20].

To make further development in the existing commercial smart mobile and cloud computing systems (Google and Bing Translation Systems), smart NLP should be built and expanded cooperatively by all researchers worldwide. Universal Words of dictionaries needed in each language have to be created and collected. Such accumulation of words for the NLP project is our common responsibility, for which every scientist has to participate to make it comprehensive. Members and research organizations connected to interlingua-based systems, for example, have to standardize their own language based on the same linguistic criteria. If the lingua franca is based on UNL, it is better to take UNL grammar as the standardization and to investigate references for all languages covered by the UNL systems.

IJCCS Vol. 13, No. 1, January 2019: $95-104$ 
Exchanging ideas between experts from one country to another should be amplified to improve skills and knowledge in computational linguistics [12]. Developing a perfect manmachine interface on smart device translation should be lifted not only as a regional issue, but also as a global challenge for both developed and developing countries. If UNL is chosen to be the model in creating web-based and App-based mobile translation machines, all members who are connected to UNL should work together as a team. For many underdeveloped and developing countries with limited research budget, there should be some funding support from developed countries to make this machine translation and NLP projects successful.

With this, all Internet users hope not very long from now, any computers and digital media devices will be capable of doing speech recognition and smart knowledge-based processing [21]. Knowledge-based processing and understanding based on exact machine translations which involves computers to taking over thought and judgment of humans can solve real time communication problems in any daily situations. In addition, it is necessary now to make the language processing based on contents of knowledge, and it is also essential to have smart translation processing to gain knowledge and to deal with information naturally. In this case, future NLP systems will be smart and clever enough to express ideas and information and to explain news and knowledge contents like a natural human being [22]-[23].

\section{CONCLUSION}

This paper presents and discusses on computers and smart devices which are recently used not only for data analyzing and processing tools, but also for Natural Language Processing and language translation machines. Apps-based software that runs on smart devices has many capabilities of smart translation with several kind of data inputs: texts, voice, image, camera, and handwriting scripts. Although accuracy and quality of its translation are acceptable enough, but further improvements and efforts from both linguistics and computer scientists are still needed. Their collaboration work is required to address various future NLP technologies, such as smart translation machine with gesture and incomplete information, speech recognition/ understanding, fast image searches and retrieval, and intelligent man-machine interface systems.

With the increasing use of Internet, rapid access to any information through wireless smart media devices (smartphones and IoT) is essential for global data transfer and information exchange. Using communication and social networking services (such as LINE, Yahoo! Together / Messenger, WhatsApp, Skype, WeChat, Twitter, Facebook, LinkedIn, Instagram, Mixi, etc.) people need to communicate quickly over long distances and across country borders to translate knowledge and information contents into their own language. Not all of them can use English or any other European languages for such global communication and interactions. However, using machine translation and NLP App software, nowadays they can easily comprehend information in any language and they can also interact with each other using their own mother tongue. This effort and technological endeavor are accomplished only to make human life more convenient and more comfortable, especially in daily global communications.

\section{REFERENCES}

[1] Fu, H., 2019, Mixed language queries in online searches, Aslib Journal of Information Management, Vol. 71 Issue: 1, pp. 72-89. Bradford, DOI:10.1108/AJIM-04-2018-0091

[2] Abdalsamad, K. \& Hossein, A., 2019, Bibliometrics of sentiment analysis literature, Journal of Information Science, Amsterdam Vol. 45, Issue: 1, pp. 3- , DOI:10.1177/0165551518761013

[3] Gunarto, H., 2004, Building Dictionary as Basic Tool for Machine Translation in Natural Language Processing Applications, Journal of Ritsumeikan Studies in Language and Culture, VOL 15, No 3, February 2004, pp: 177-185. 
[4] Wibawa, A.P., Nafalski, A., 2013, Indonesian-to-Javanese Machine Translation, International Journal of Innovation, Management and Technology, Vol. 4, No. 4, August 2013, pp: 451-454.

[5] Abdiansah, A., Azhari, A., and Sari, A.K., 2018, Survey on Answer Validation for Indonesian Question Answering System (IQAS), Int. Journal Intelligent Systems and Applications, VOL. 4, pp. 68 - 78, DOI: 10.5815/ijisa.2018.04.08

[6] Kaiping, A.G., Klamer, M., 2018, LexiRumah: An online lexical database of the Lesser Sunda Islands, Leiden University Centre for Linguistics, Netherland, accessed on 5 January 2019 from https://doi.org/10.1371/journal.pone.0205250

[7] Biçici, E., Specia, L., 2015, QuEst for High Quality Machine Translation, The Prague Bulletin of Mathematical Linguistics, NUMBER 103, April 2015, pp. 43-64, DOI:10.1515/pralin-2015-0003

[8] Arcan, M., Turchi, M., Tonelli, S., Buitelaar, P., 2017, Leveraging bilingual terminology to improve machine translation in a CAT environment, J. of Natural Language Engineering; Cambridge Sep 2017, Vol. 23, Issue: 5, pp. 763-788. DOI:10.1017/S1351324917000195

[9] Das, B., Majumder, M., Phadikar, S., 2018, A Novel System for Generating Simple Sentences from Complex and Compound Sentences, I.J. Modern Education and Computer Science, 2018: 1, pp. 57-64, DOI: 10.5815/ijmecs.2018.01.06

[10] Moorkens, J., Way, A., 2016, Comparing Translator Acceptability of TM and SMT Outputs, Baltic Journal of Modern Computing, Vol. 4, Issue: 2, pp. 141-151.

[11] Linell, P., 2013, Distributed Language Theory, with or without Dialogue, Journal of Language Sciences, Elsevier, Volume 40, November 2013, pp. 168-173.

[12] Taghbalout, I., Allah, F.A., Marraki, M.E., 2018, Towards UNL-based machine translation for Moroccan Amazigh language, International Journal of Computational Science and Engineering; Geneva Vol. 17, Issue: 1, pp. 43-54. DOI:10.1504/IJCSE.2018.094418

[13] Gunarto, H., 2018, Kanji Learning. http://www.gunarto.org/kanji.php. accessed date 22 Nov. 2018.

[14] Tu, Z., 2016, DHT-based collaborative web translation, University of Cincinnati, ProQuest Dissertations Publishing.

[15] Abriata, L.A., 2017, Web Apps Come of Age for Molecular Sciences, J. Informatics; Basel Vol. 4, Issue: 3, pp. 28- DOI:10.3390/informatics4030028

[16] Gao, L., Gao, D., Xiong, N., Lee, C., 2018, CoWebDraw: a real-time collaborative graphical editing system supporting multi-clients based on HTML5, J. Multimedia Tools and Applications; Dordrecht Vol. 77, Issue: 4, pp. 5067-5082. DOI:10.1007/s11042-0175242-4

[17] Voutilainen, J.P., Mattila, A.L., Systä, K., Mikkonen, T., 2016, HTML5-based Mobile Agents for Web-of-Things, J. Informatica, suppl. Engineering and Applications; Ljubljana Vol. 40, Issue: 1, pp. 43-51.

[18] Mobinizad, M.M., 2018, The Use of Mobile Technology in Learning English Language, J. Theory and Practice in Language Studies; London Vol. 8, Issue: 11, pp. 1456-1468. DOI:10.17507/tpls.0811.10

[19] Dale, R., 2019, Law and Word Order: NLP in Legal Tech, J. Natural Language Engineering; Cambridge Vol. 25, Issue: 1, pp. 211-217. DOI:10.1017/S1351324918000475

[20] Oprea, S., Tudorica, B.G., Belciu, A., Botha, I., 2017, Internet of Things, Challenges for Demand Side Management, Informatica Economica; Bucharest Vol. 21, Iss. 4, pp. 59-72.

[21] Qin, C.X., Qu, D., Zhang, L.H., 2018, Towards end-to-end speech recognition with transfer learning, EURASIP Journal on Audio, Speech, and Music Processing, Vol.18, pp. 1-9, DOI: https://doi.org/10.1186/s13636-018-0141-9

[22] Suhr, A., Lewis, M., Yeh, J., Artzi, Y., 2018, Evaluating Visual Reasoning Through Grounded Language Understanding, AI Magazine; Canada Vol. 39, Iss. 2, pp. 45-52.

[23] Israni, S.T., Verghese, A., 2019, Humanizing Artificial Intelligence, JAMA: The Journal of the American Medical Association; Chicago Vol. 321, Issue: 1, pp. 29-, DOI:10.1001/jama.2018.19398

IJCCS Vol. 13, No. 1, January 2019 : 95 - 104 